\title{
Primary Large B-cell Lymphoma of the Ovary Mimicking Meigs Syndrome: A Case Report
}

\author{
Hazuki Kagawa ${ }^{1}$, Tsuneko Ikeda ${ }^{2}$, Hiroshi Takagi ${ }^{1}$, Satoshi Ichigo ${ }^{1}$ and Atsushi Imai ${ }^{1 *}$ \\ ${ }^{1}$ Departments of Obstetrics and Gynecology, Matsunami General Hospital, Japan \\ ${ }^{2}$ Departments of Pathology, Matsunami General Hospital, Japan
}

*Corresponding author: Atsushi Imai, Department of Obstetrics and Gynecology, Matsunami General Hospital, 185-1 Dendai, Kasamatsu, Gifu 501-6062, Japan

\section{ARTICLE INFO}

Received: 陆 July 16, 2019

Published: 蔧 July 22, 2019

Citation: Hazuki K, Tsuneko I, Hiroshi T, Satoshi I, Atsushi I. Primary Large B-cell Lymphoma of the Ovary Mimicking Meigs Syndrome: A Case Report. Biomed J Sci \& Tech Res 19(5)-2019. BJSTR. MS.ID.003368.

\begin{abstract}
Primary ovarian lymphoma is a relatively rare entity, and its diagnosis is generally unpredicted until histological examination completed. A 73-year-old female patient presented with 1-month history of progressive pleural effusion and ascites. Abdomen and chest imaging revealed a $10-\mathrm{cm}$ sized heterogenous solid mass arising from the right ovary with large amount of ascites and right pleural effusion. With a suspicion of Meigs syndrome, she underwent right salpingo-oophorectomy. Histophathological examination along with immunohistochemistry of the excised tissue revealed diffuse large B-cell lymphoma. The staging work-up was negative, which directed to the diagnosis of primary ovarian lymphoma. Even under intensive chemotherapy, the rarity of our patient characteristics led us to mention.
\end{abstract}

Keywords: Primary Ovarian Lymphoma; B-Cell Lymphoma; Ascites; Pleural Effusion; Meigs Syndrome

\section{Introduction}

Primary ovarian lymphoma has been described as a very rare occurrence accounting for $0.5-1 \%$ of all non-Hodgkin's lymphoma, but secondary involvement of the ovaries by lymphoma may occur more frequently at late stage (20-30\%) [1-4]. Primary extranodal lymphoma is less aggressive as 5 years survival rate is $80 \%$ whereas it is 30\% in secondary lymphoma [5]. The difference between them is critical from a prognostic view [6]. Primary ovarian lymphomas present as solid mass of the ovary with a $1.5 \%$ incidence of all ovarian malignancies $[2,4,7]$. The most common clinical presentations of ovarian lymphoma include general fatigue, pelvic pain, bowel obstruction and abdominal mass with rapid growth [2,4]. It also shows varied symptoms with more difficult differential diagnosis $[8,9]$. We present a case of primary diffuse B-cell lymphoma of right ovary in an elderly woman who initially presented with pleural effusion and ascites mimicking characteristic features of Meigs syndrome [10-12].

\section{Case Report}

A 73-year-old Japanese null gravid woman presented with 1-month history of progressive shortness of breast. She had previously been in good health with no medical history of note. She took no regular medication and had no family medical history of note. A computed tomography scan confirmed the presence of a large right pleural effusion. Her abdominal and pelvic MR images demonstrated a solid heterogenous right adnexal mass (11x8x9 cm) situated in the cul-de-sac as well as a large amount of free ascitic fluid (Figure 1). The left ovary and uterus were of age-matched atrophic appearance. Laboratory studies showed elevated lactate dehydrogenase level of $174 \mathrm{IU} / \mathrm{L}$ (reference range, 106-220 IU/L), elevated CA125 level of $1200 \mathrm{U} / \mathrm{mL}(<35 \mathrm{U} / \mathrm{mL})$, and elevated soluble-IL-2R level of $4090 \mathrm{U} / \mathrm{ml}(220-530 \mathrm{U} / \mathrm{mL})$. Other laboratory data were not contributory. The possible diagnosis included Meigs syndrome and other malignant ovarian tumors. With these data and because of further deterioration of the patient's clinical condition, it was decided to perform an exploratory laparotomy. During surgery, enlarged and smooth-surfaced mass of the right ovary and a large amount of clear ascitic fluid were seen. The peritoneum was smooth and free of any visible implants.

The ovarian mass was removed, and ascitic fluid cytology and cultures were sent. Postoperatively the patient made an favorite recovery. Two weeks later, the level of soluble-IL-2R decreased to $1470 \mathrm{U} / \mathrm{ml}$. On pathological examination the ovarian mass measured $10 \times 8.5 \times 8.5 \mathrm{~cm}$ and weighed $450 \mathrm{~g}$. The outer surface looked predominantly smooth with a focus of slight adhesive area. 
The cut surface was solid, gray to tan in color and appeared focally hemorrhagic and necrotic. The diagnosis of large B-cell lymphoma was made on histological examination, as shown in Figure 2, which was later confirmed by immunohistochemistry CD20, CD5 and CD10 was positive in tumor cells. Ki67 was also positive but cytokeratin negative. There was no involvement to fallopian tube and tumor capsule. The result of ascites and pleural effusion were negative. The staging work-up was negative, which directed to the diagnosis of primary ovarian lymphoma. The patient was transported to a specialized hematologic oncology center for immediate initiation of chemotherapy and further management.

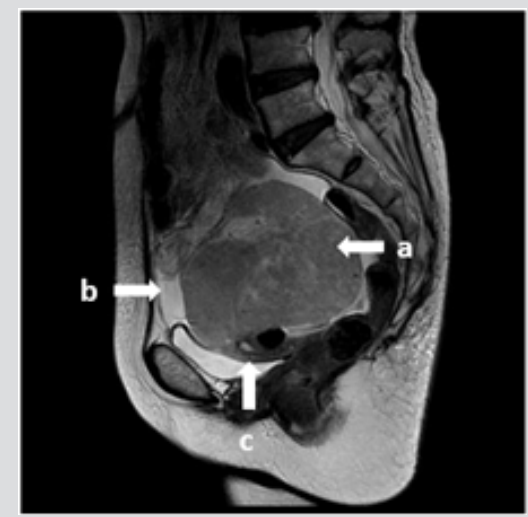

Figure 1: Sagittal T2-weighted MR image showing a solid heterogenous mass (arrow a) arising from the right ovary. Surrounding ascites (arrow b) and atrophic uterus (arrow c) were visible.

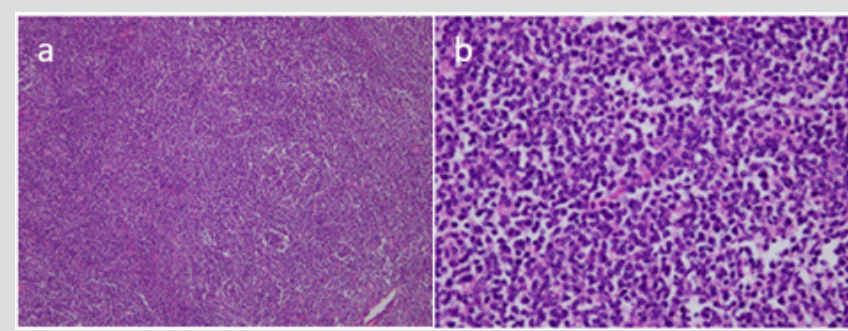

Figure 2: Photomicrographs showing large B-cell lymphoma with an infiltrate of medium-sized atypical lymphocytes (H\&E stain, x100 (a) and x400 (b)).

\section{Discussion}

Our patient presented initially with characteristic features of Meigs syndrome including a pleural effusion, ascites and solid ovarian tumor. The syndrome has a classical triad of features: a benign ovarian tumor (usually a fibroma) combined with ascites and pleural effusion (generally right-side) $[10,12,13]$. The condition is seen in association with less than $1 \%$ of ovarian tumors, very rare in younger women but more common in elderly women with an average age of about 60 years. The common differential diagnoses of solid ovarian tumors include Krukenberg tumors, granulosa cell tumors, thecomas, fibromas, dysgerminomas, teratomas, and Brenner tumors. A definitive pathological diagnosis was made after pathological examination and immunostaining. CD20, CD10 and scattered CD5 positivity in our case suggested a B-cell lymphoblastic lymphoma. Once it is disseminated, it is difficult to determine the lymphoma is primary or secondary. Although the ovary is often a site of secondary lymphomatous spread [1-4], our patient had no evidence of extraovarian involvement on staging investigations: negative cytological findings of pleural effusion, the operative findings of the solitary large mass originating ovary without any peritoneal implants, and postoperative decrease of soluble IL2R level. The pathogenesis of the production of ascitic and pleural effusion in Meigs syndrome in uncertain. It has been postulated that the fluid results from an imbalance between vascular supply and lymphatic drainage in these large tumors.

As another explanation, the process is intrinsically inflammatory, with an earlier report demonstrating elevations of some inflammatory molecules and cytokines, however the detailed underlying mechanism is still unclear $[14,15]$. The occurrence of pleural effusion is thought to be secondary to the passage of ascites to pleural space through the diaphragm or diaphragmatic lymph vessels, which occur commonly on the right side as seen in our case. We do not answer the pathogenesis of the production of pleural effusion through our case. However, our experience may be an important reminder that ovarian lymphoma, despite a rare entity, can mimic Meigs syndrome on clinical and imaging manifestations. Early diagnosis with high index of suspicion can avoid submitting the patient to unnecessary investigations and delays in management.

\section{Disclosure Statement}

The authors declare no conflict of interest.

\section{References}

1. Guvvala S, Sakam S, Niazi M, Skaradinskiy Y (2017) Case of primary bilateral diffuse large B-cell lymphoma of the ovary with plasmablastic features in an HIV-negative female patient. BMJ.

2. Nasioudis D, Kampaktsis P, Frey M, Witkin SS, Holcomb K (2017) Primary lymphoma of the female genital tract: An analysis of 697 cases. Gynecol Oncol 145: 305-309.

3. Sun J, Zhang J, Ling $Q$ Luo $Y$, Wu S, et al. (2015) Primary diffuse large B-cell lymphoma of the ovary is of a germinal centre B-cell-like phenotype. Virchows Arch 466: 93-100.

4. Vang R, Medeiros L, Fuller G, Sarris AH, Deavers M (2001) Non-Hodgkin's lymphoma involving the gynecologic tract: a review of 88 cases. Adv Anat Pathol 8: 200-217.

5. Crasta J, Vallikad E (2009) Ovarian lymphoma. Indian J Med Paediatr Oncol 30: 28-30.

6. Weingertner A, Hamid D, Roedlich M, Baldauf J (2004) Non-Hodgkin malignant lymphoma revealed by an ovarian tumor case report and review of the literature. Gynecol Oncol 95: 750-754.

7. Dimopoulos M, Daliani D, Pugh W, Gershenson D, Cabanillas F, et al. (1997) Primary ovarian non-Hodgkin's lymphoma: outcome after treatment with combination chemotherapy. Gynecol Oncol 64: 446-450.

8. Bianchi P, Torcia F, Vitali M, Cozza G, Matteoli M, et al. (2013) An atypical presentation of sporadic ovarian Burkitt's lymphoma: case report and review of the literature. J Ovarian Res 6: 46.

9. Ferry J (2006) Burkitt's lymphoma: clinicopathologic features and differential diagnosis. Oncologist 11(4): 375-383. 
10. Iyer R, Chow J, El Bahrawy M, Savage P (2013) Meigs syndrome presenting with axillary vein thrombosis and lymphadenopathy: a case report. J Med Case Rep 7: 182.

11. Krenke R, Maskey Warzechowska M, Korczynski P, Zielinska Krawczyk M, Joanna Klimiuk, et al. (2015) Pleural effusion in Meigs' syndrometransudate or exudate? systematic review of the literature. Medicine (Baltimore) 94(49): 2114.

12. Meigs J, Cass J (1937) Fibroma of the ovary with ascites and hydrothorax: with a report of seven cases. Am J Obstet Gynecol 33(2): 249-267.

ISSN: 2574-1241

DOI: 10.26717/BJSTR.2019.19.003368

Atsushi Imai. Biomed J Sci \& Tech Res

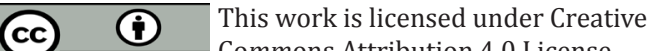

Submission Link: https://biomedres.us/submit-manuscript.php
13. Prat J, Scully R (1981) Cellular fibromas and fibrosarcomas of the ovary: a comparative clinicopathologic analysis of seventeen cases. Cancer 47(11): 2663-2670

14. Abramov Y, Anteby S, Fasouliotis S, Barak V (2002) The role of inflammatory cytokines in Meig's Syndrome. Obstet Gynecol 99(5): 917919.

15. Meigs J (1954) Fibroma of the ovary with ascites and hydrothorax; Meigs' syndrome. Am J Obstet Gynecol 67(5): 962-985.

$\begin{array}{ll}\text { BIOMEDICAL } & \text { Assets of Publishing with us } \\ \text { RESEARCHES } & \text { - Global archiving of articles } \\ & \text { - Immediate, unrestricted online access } \\ & \text { - Rigorous Peer Review Process } \\ \end{array}$

